Acta Crystallographica Section D

Biological

Crystallography

ISSN 0907-4449

Irene S. Gonsalvez, Michail N. Isupov and Jennifer A. Littlechild*

Schools of Chemistry and Biological Sciences, University of Exeter, Exeter EX4 4QD, England

Correspondence e-mail:

j.a.littlechild@exeter.ac.uk

\title{
Crystallization and preliminary X-ray analysis of a $\gamma$-lactamase
}

\begin{abstract}
An enzyme from Comomonas acidovorans has been isolated that is specific for the stereospecific hydrolysis of $(+) \gamma$-lactam. This so-called $(+) \gamma$-lactamase has important applications in biotransformation reactions. The enzyme has been crystallized by vapour-phase diffusion using polyethylene glycol 4000 as a precipitant. Addition of a detergent, $\beta$-octylglucoside, was found to be essential for obtaining diffraction-quality crystals. The crystals grow in the space group $P 1$, with unit-cell parameters $a=63.0, b=93.2, c=152.4 \AA$, $\alpha=104.3, \beta=92.6, \gamma=108.5^{\circ}$, and diffract to $2 \AA$ resolution using synchrotron radiation. Native data from these crystals have been collected to $2.4 \AA$.
\end{abstract}

Received 10 August 2000 Accepted 9 November 2000

\section{Introduction}

The enzyme $(+) \gamma$-lactamase catalyses the specific hydrolysis of $(+) \gamma$-lactam with no activity against the (-) isomer. It is industrially used for the production of optically pure (-) $\gamma$-lactam (Taylor et al., 1993).<smiles>O=C1NC2C=CC1C2</smiles>

racemic $\gamma$-lactam
(+) $\gamma$-lactamase<smiles>O=C1NC2C=CC1C2</smiles>

(-) $\gamma$-lactam

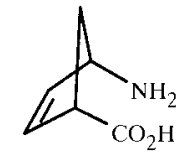

(+) amino acid
Analogues of carbocyclic purine and pyrimidine nucleosides are of use as antiviral compounds. The pure $(-) \gamma$-lactam produced by the scheme above has been used as a building block for important drugs such as Carbovir, an anti-HIV agent (Taylor et al., 1993).

Soil samples have been screened for $(+) \gamma$ lactamase activity (Brabban et al., 1996) and recently a stable form of the enzyme has been isolated from $C$. acidovorans. This $(+) \gamma$-lactamase has now been cloned, sequenced and overexpressed in Escherichia coli (Taylor et al., 1999). This enzyme shows high sequence identity to a formamidase from Methylophilus methylotropus (63\%) (Wyborn et al., 1994) and an acetamidase from Mycobacterium smegmatis (56\%) (Mahenthiralingam et al., 1993) and no detectable sequence homology to other described amidases. The $(+) \gamma$-lactamase does not contain the so-called amidase signature sequence that has been described by Kobayashi et al. (1997) and therefore belongs to a distinct class of hydrolytic enzymes for which there is no three-dimensional structural information. The identification and location of the active site for this group of enzymes is important to our understanding of their reaction mechanism and substrate specificity.

The elucidation of the three-dimensional structure of the $(+) \gamma$-lactamase described in this paper will provide information on the diversity of amidase-related enzymes. It will also establish whether the $\gamma$-lactamases have any relationship to the well characterized $\beta$-lactamase enzymes despite them having no apparent sequence homology.

\section{Experimental}

\subsection{Purification of recombinant $\gamma$-lactamase}

E. coli $\mathrm{DH} 5 \alpha$ cells harbouring the plasmid pUC19 containing the $(+) \gamma$-lactamase gene were supplied by Chirotech Ltd, Cambridge Science Park, England. The purification of the enzyme was carried out as previously described (Brabban et al., 1996) with some modifications. Cells were broken by sonication and after clarification the crude extract was precipitated with ammonium sulfate (enzyme grade). The ammonium sulfate pellet was resuspended in a minimum of buffer $(0.01 M$ Tris- $\mathrm{HCl} \mathrm{pH} 7.0$, $1.5 M$ ammonium sulfate) and applied directly to a HiLoad 26/10 Phenyl Sepharose column (Pharmacia) equilibrated with the same buffer. Protein was eluted with a decreasing gradient from 100 to $0 \%$ ammonium sulfate, $0.01 M$ Tris- $\mathrm{HCl} \mathrm{pH} 7.0$ over $600 \mathrm{ml}$. Active fractions were pooled and dialysed overnight against $0.01 M$ Tris- $\mathrm{HCl} \mathrm{pH} 7.0$ to remove ammonium sulfate before being applied to a HiLoad 26/10 FFQ column (Pharmacia). Protein was eluted with a linear gradient of 0 to $0.1 \mathrm{M} \mathrm{NaCl}$, $10 \mathrm{~m} M$ Tris- $\mathrm{HCl}$ pH 7.0 over ten bed volumes. The active fractions were pooled and concentrated using $80 \%$ ammonium sulfate. After 
centrifugation, the pellet was resuspended in a minimum of $10 \mathrm{~m} M$ Tris- $\mathrm{HCl} \mathrm{pH} 7.0$ and applied to a Superdex200 16/60 gel-filtration column (Pharmacia). Active fractions from this final step were pooled and concentrated by centrifugation using Amicon Centricon concentrators (10 kDa cutoff). The purity of the protein was analysed by SDS-PAGE and the concentration of the protein was determined by the Bradford assay (Bradford, 1976). Bovine serum albumin (SigmaAldrich Co.) was used to generate a standard curve.

\subsection{Characterization}

Lactamase activity was determined by HPLC. For this, 10-100 $\mu \mathrm{l}$ of enzyme was added to $890-800 \mu \mathrm{l}$ of buffer, $0.1 \mathrm{~m} M$ Tris$\mathrm{HCl} \mathrm{pH}$ 7.5. The reaction was initiated by the addition of $100 \mu \mathrm{l}$ of racemic lactam and terminated after an incubation period of $1 \mathrm{~h}$ with the addition of $900 \mu$ of HPLC buffer, 50:50 methanol, $10 \mathrm{~m} M$ potassium phosphate $\mathrm{pH} 7.0$ to a $100 \mu \mathrm{l}$ aliquot of the incubated reaction mixture.

Amidase activity was determined colorimetrically by measuring the rate of ammonia formation at $\mathrm{pH} 6.0$ with $50 \mathrm{mM}$ acetamide as the substrate at $310 \mathrm{~K}$ (Silman et al., 1989). The absorbance was measured at $630 \mathrm{~nm}$ and the amount of ammonia released was determined from a standard curve with ammonium chloride. Quantitative determination of production of ammonia was also monitored by absorption at $340 \mathrm{~nm}$ using the Sigma Diagnostics Ammonia reagents kit No. 171-UV.

\subsection{Inhibition studies}

Enzyme samples were incubated at $298 \mathrm{~K}$ for $1 \mathrm{~h}$ with each inhibitor: BAM (benzamidine), PMSF (phenylmethyl sulfonyl fluoride), IAA (iodoacetic acid) and EDTA (ethylenediamine tetraacetic acid). Residual activity was then determined using the HPLC assay described above.

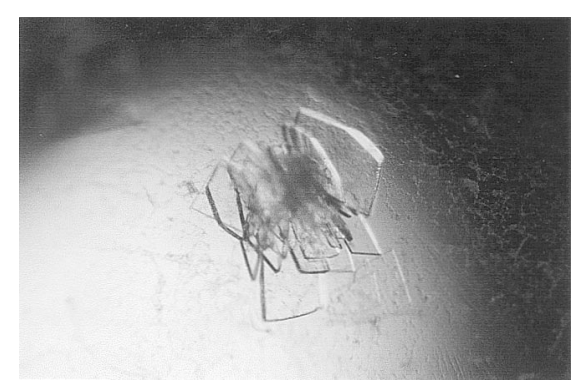

Figure 1

Triclinic crystals of $(+) \gamma$-lactamase.

\subsection{Sedimentation equilibrium analysis}

Sedimentation equilibrium analysis of purified $(+) \gamma$-lactamase was carried out by the BBSRC National Centre for Macromolecular Hydrodynamics at the University of Nottingham. The $(+) \gamma$-lactamase sample was monitored by sedimentation equilibrium at concentrations of 0.5 and $1 \mathrm{mg} \mathrm{ml}^{-1}$ in buffer (10 m $M$ Tris- $\mathrm{HCl} \mathrm{pH} 7.0)$.

\subsection{Mass spectrometry}

Purified $(+) \gamma$-lactamase was concentrated to $1 \mathrm{mg} \mathrm{ml}^{-1}$ and $500 \mu \mathrm{g} \mathrm{ml}^{-1}$ for massspectrometry analysis. The sample was dialysed against $10 \mathrm{~m} M$ Tris- $\mathrm{HCl} \mathrm{pH}$ 7.0. Analysis by electrospray mass spectrometry was carried out at the Protein Facility, University of Aberdeen.

\subsection{Crystallization and data collection}

The $(+) \gamma$-lactamase was crystallized by both the hanging-drop and sitting-drop vapour-diffusion techniques. For crystallization experiments, the protein was concentrated in $10 \mathrm{~m} M$ Tris- $\mathrm{HCl}$ pH 7.0, $0.1 \mathrm{M} \mathrm{NaCl}$ to $19 \mathrm{mg} \mathrm{ml}^{-1}$. Protein concentrations were estimated using the extinction coefficient derived for $\gamma$-lactamase of $E_{280}^{1 \%}=10$ (Gill \& von Hippel, 1990). After extensive screening of crystallization conditions, crystals suitable for X-ray studies were obtained from sitting drops containing $5 \mu \mathrm{l}$ protein, $4 \mu \mathrm{l}$ reservoir (as below) and $1 \mu \mathrm{l}$ of $10 \% \beta$ OG equilibrated against $1 \mathrm{ml}$ reservoir solution containing 10-19\% PEG 4000, $0.1 M$ sodium acetate $\mathrm{pH} 5.6$ at $290 \mathrm{~K}$. The crystals were harvested into a mother liquor containing 35-40\% PEG 400, $10 \mathrm{~m} M$ Tris$\mathrm{HCl}, 0.1 M \mathrm{NaCl}, 0.1 M$ sodium acetate $\mathrm{pH}$ 5.6 and $1 \% \beta \mathrm{OG}$, which was also used as a cryoprotectant. In-house data were collected both at $120 \mathrm{~K}$ and at room temperature on a Siemens HiStar area detector using $\mathrm{Cu} K \alpha$ radiation from a rotating-anode generator and were processed using the dataintegration program SAINT (SAINT, 1993). Synchrotron data were collected at $100 \mathrm{~K}$ at station BW7A at the EMBL Hamburg outstation using a MAR CCD detector and were processed using the DENZO/ $S C A L E P A C K$ program suite (Otwinowski \& Minor, 1997).

\section{Results and discussion}

\subsection{Purification and characterization}

The purified protein sample ran as a single band on SDS-PAGE, with an apparent mobility equivalent to a molecular mass of $43 \mathrm{kDa}$. When analysed by electrospray
Table 1

Summary of data-collection statistics.

Values in parentheses are given for the outer resolution shell.

\begin{tabular}{ll}
\hline Resolution range $(\AA)$ & $20-2.4(2.44-2.4)$ \\
Completeness (\%) & $95.3(81.8)$ \\
$R_{\text {sym }}$ & $0.073(0.25)$ \\
$\langle I\rangle /\langle\sigma I\rangle$ & $10.2(2.5)$ \\
Redundancy & $2.1(1.9)$ \\
Unique reflections & 117493 \\
$B$ factor, data from Wilson plot $\left(\AA^{2}\right)$ & 34.5 \\
\hline
\end{tabular}

$\dagger R_{\text {sym }}=\sum_{h} \sum_{J}\left|\left\langle I_{h}\right\rangle-I_{J}(h)\right| / \sum_{h} \sum_{I} I(h)$, where $I(h)$ is the intensity of reflection $h . \sum_{h}$ is the sum over all reflections and $\sum_{J}$ is the sum over $J$ measurements of the reflection.

mass spectrometry, the molecular weight was determined to be $44294 \mathrm{Da}$. Sedimentation analysis gave a molecular weight of $175300 \mathrm{Da}$, indicating that the native form of the enzyme is a tetramer. Resolution of the racemic lactam on the HPLC column monitoring the lactamase assay is complete within $3.5 \mathrm{~min}$, giving a conversion of $11.7 \mu \mathrm{g}$ of resolved product per microgram of enzyme.

Sequence alignment using the BLAST program (Altschul et al., 1997) indicated that the Comomonas lactamase is $63 \%$ identical to Met. methylotrophus formamidase and $56 \%$ identical to Myc. smegmatis acetamidase. This is in agreement with the observed amidase activity of the purified protein, which was found to be $0.07 \mu M \mathrm{NH}_{3}$ per minute per microgram of enzyme (Silman et al., 1989). The $(+) \gamma$-lactamase was inhibited by PMSF and BAM, which suggests the presence of a serine residue in

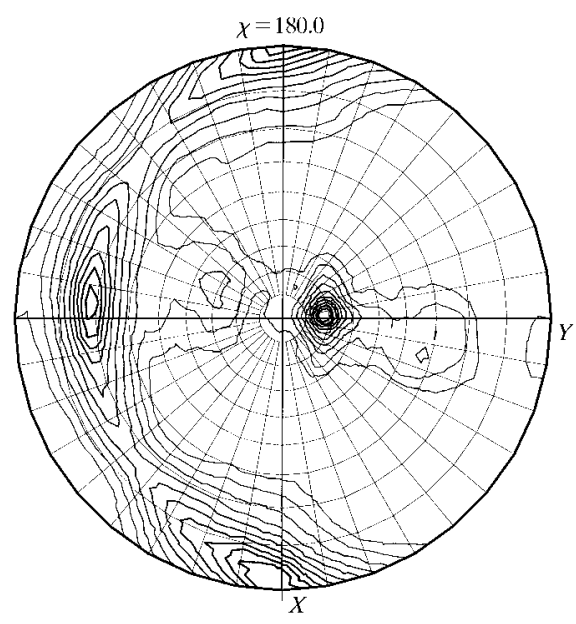

Figure 2

Self-rotation function calculated for $\kappa=180^{\circ}$ calculated at $10-5 \AA$ resolution with an integration radius of $30 \AA$ by the program MOLREP (Vagin \& Teplyakov, 1997) suggests the point-group symmetry of the $(+) \gamma$-lactamase molecule to be 222 , which is in agreement with the results of sedimentation studies which suggest the $(+) \gamma$-lactamase molecule to be a tetramer. 
the active site of the enzyme which may play a role as a nucleophile attacking the amide $\mathrm{C}$ atom. No inhibition was observed with the metalloprotease inhibitor EDTA or the cysteine protease inhibitor IAA.

\subsection{Crystallization and preliminary $X$-ray analysis}

Plate-like crystals with maximum dimensions of $1.0 \times 0.6 \times 0.2 \mathrm{~mm}$ as shown in Fig. 1 grew within 8 d from $10-19 \%$ PEG 4000 in $0.1 M$ sodium acetate $\mathrm{pH} 5.6$ and $1 \% \beta$ OG. Addition of the $\beta \mathrm{OG}$ detergent was essential for obtaining crystals of diffraction quality. The diffraction extended beyond $2 \AA$ resolution; however, time restraints limited data collection to $2.4 \AA$ (Table 1). The space group was identified as $P 1$, with unit-cell parameters $a=63.0, b=93.2$, $c=152.4 \AA, \alpha=104.3, \beta=92.6, \gamma=108.5^{\circ}$. The crystals diffracted to $2.8 \AA$ resolution inhouse. The self-rotation function calculated from the data using the program MOLREP (Vagin \& Teplyakov, 1997) shows strong features at $\kappa=180^{\circ}$ (Fig. 2). There are three non-crystallographic dyads normal to each other, which indicates 222 molecular pointgroup symmetry. This is consistent with the tetramer suggested experimentally from the sedimentation studies described above. One $(+) \gamma$-lactamase tetramer per asymmetric unit would give a solvent content of $75 \%$, which is considered unusual for the normally highly packed triclinic space-group symmetry (Andersson \& Hovmoller, 2000). Two tetramers per asymmetric unit would give a solvent content of $50 \%$. Since the selfrotation function features only three noncrystallographic dyads, the axes of the two tetramers would appear to be nearly parallel. The two tetramers are likely to be in similar orientation, as the self-rotation function does not show strong features at $\kappa=90^{\circ}$. Inspection of the native Patterson synthesis of the data (Collaborative Computational Project, Number 4, 1994) calculated between 20 and $5 \AA$ resolution showed a peak 0.15 of the origin at $u=0.75$, $v=0.46, w=0.46$. Whether this peak is a pseudotranslation vector relating two different $\gamma$-lactamase tetramers within the triclinic unit cell remains to be determined.

A search for suitable heavy-atom derivatives for phasing purposes is currently under way.

Dr Kornelia Jumel is thanked for her help in carrying out the sedimentation studies at the BBSRC National Centre for Macromolecular Hydrodynamics at the University of Nottingham. Dr Steve Taylor and Dr Rob Brown are thanked for providing the cell paste and cloning of the $(+) \gamma$-lactamase enzyme. This work was supported by the Biotechnology and Biological Sciences Research Council (BBSRC) in the form of a postdoctoral fellowship to MNI. We also thank the European Union for support of the work carried out at EMBL Hamburg through the HCMP Access to Large Installations Project, contract No. CHGE-CT93-
0040. ISG would like to thank the School of Chemistry at Exeter and her parents for financial support.

\section{References}

Altschul, S. F., Madden, T. L., Schaffer, A. A., Zhang, J., Zhang, Z., Miller, W. \& Lipman, D. J. (1997). Nucleic Acids Res. 25, 3389-3402.

Andersson, K. M. \& Hovmoller, S. (2000). Acta Cryst. D56, 789-790.

Brabban, A. D., Littlechild, J. \& Wisdom, R. (1996). J. Indust. Microbiol. 16, 8-14.

Bradford, M. M. (1976). Anal. Biochem. 72, 248 254.

Collaborative Computational Project, Number 4 (1994). Acta Cryst. D50, 760-763.

Gill, S. C. \& von Hippel, P. H. (1990). Anal. Biochem. 182, 319-326.

Kobayashi, M., Fujiwara, Y., Goda, M., Komeda, H. \& Shimizu, S. (1997). Proc. Natl Acad. Sci. USA, 94, 11986-11991.

Mahenthiralingam, E., Draper, P., Davis, E. O. \& Colston, J. (1993). J. Gen. Microbiol. 139, 575 583.

Otwinowski, Z. \& Minor, W. (1997). Methods Enzymol. 276, 307-326.

SAINT (1993). SAINT Software Reference Manual, Madison, Wisconsin, USA.

Silman, N. J., Carver, M. A. \& Jones, C. W. (1989) J. Gen. Microbiol. 135, 3153-3164.

Taylor, S. J. C., Brown, R. C., Keene, P. A. \& Taylor, I. N. (1999). Bioorg. Med. Chem. 7 , 2163-2168.

Taylor, S. J. C., McCague, R., Wisdom, R., Lee, C., Dickson, K., Ruecroft, G., O'Brien, F., Littlechild, J., Bevan, J., Roberts, S. M. \& Evans, C. T. (1993). Tetrahedron Asymmetry, 4, 1117-1128.

Vagin, A. \& Teplyakov, A. (1997). J. Appl. Cryst. 30, 1022-1025.

Wyborn, N. R., Scherr, D. J. \& Jones, C. W. (1994) Microbiology, 140, 191-195. 